\title{
Impact of dietary intervention with a functional food supplement to combat anemia - the blood iron metabolic disorder among the coffee plantation laborers
}

\author{
Vasantha Esther Rani $^{1}{ }^{*}$ and Samuel Paulraj ${ }^{2}$ \\ ${ }^{1}$ Department of Home Science with Food Biotechnology, Fatima College (Autonomous) \\ Madurai, Tamil Nadu, India; ${ }^{2}$ School of Energy Sciences, Madurai Kamaraj University, \\ Madurai, Tamil Nadu, India
}

*Corresponding Author: Vasantha Esther Rani, PhD, Associate Professor and Department Head of Home Science with Food Biotechnology, Fatima College (Autonomous) Madurai, Tamil Nadu, India, Tamil Nadu, India

Submission date: December 9, 2012; Acceptance date: January 24, 2013; Publication date: January 27, 2013

\section{ABSTRACT}

Objective: To assess the nutritional status and other nutrition related problems of the workers. To design, implement and evaluate the impact of dietary intervention for the nutritional metabolic disorder which is directly related to productivity.

Background: Indian economy greatly relies on agriculture. Agriculture is set to play a more dynamic role in the economy. The present study focuses on the nutritional status with special reference to the blood iron profile of manual coffee plantation laborers belonging to Kodaikannal, Tamil Nadu, India. The outcome of this study on the dietary intervention, based on nutritional picture of coffee plantation laborers, will have a nationwide application because of the simplified, stable coffee plantation operations throughout India.

Method: Experiments were carried out in three phases. In the first phase, the personal background of the laborers was assessed. In the second phase, the nutritional and health status of the laborers, through dietary survey comprising 24 Hour Food Recall record and weighment of cooked food consumed for three consecutive days, clinical and biochemical profile were studied. The serum iron was measured with the total iron binding capacity, from which the transferrin saturation was calculated. In the third phase, dietary intervention was implemented with a nutrient rich nutraceutical food supplement - spirulina incorporated soup. The supplementation was extended for a period of 120 days. The subjects were grouped into control and the experimental group. The control group was given plain soup and the experimental group was administered with soup incorporated with spirulina. The impact of intervention on the biochemical and nutritional profile of the laborers was reassessed in similar working conditions.

Results: A deficit of $0.1 \mathrm{mg}$ to $0.3 \mathrm{mg}$ of iron intake per $\mathrm{kg}$ body weight in the male and female laborers was observed when compared to their RDA The clinical pictures reveal that 
94 percent suffered from anemia, 56 percent showed anemic signs of spooning of nails (koilonychyia), 36 percent of the subjects had glossitis (mouth ulcer), 16 percent suffered from bleeding gums, 4 percent had cheilosis (ulceration of tongue) and 28 percent had angular stomatitis. The average hemoglobin level was $8.6 \pm 1.12 \mathrm{~g} / \mathrm{dl}$ for men and $8.1 \pm 1.01 \mathrm{~g} / \mathrm{dl}$ for women which are 28 and 37 percent less than normal respectively. Dietary intervention of $5 \mathrm{~g}$ of spirulina in $150 \mathrm{ml}$ of soup had significantly improved the blood iron profile. Among the male laborers, 10 percent who suffered from severe anemia with $7.9 \mathrm{~g} . \mathrm{dl}^{-1}$ hemoglobin before intervention were shifted to moderate levels of 9.4 g. $\mathrm{dl}^{-1}, 30$ percent who suffered from mild anemia were shifted to normal ones and among 60 percent of male laborers who were moderately anemic, 50 percent reverted to normalcy.

Conclusion: In the present study it was observed that the habitual dietary intake showed deficiency in consumption of iron rich foods and the clinical picture revealed the signs and symptoms of anemia The blood iron profile - Hemoglobin (Hb), Serum Iron, Transferrin Saturation, Serum Ferritin, Total Iron Binding Capacity (TIBC) and Unsaturated Iron Binding Capacity (UIBC) were greatly influenced by dietary intervention with the functional food Spirulina incorporated soup The blood hemoglobin content increased by 21 percent i.e from 10.9 to $13.3 \mathrm{~g} . \mathrm{dl}^{-1}$. Serum iron, serum ferritin and transferrin levels showed a consistent and progressive rise while TIBC and UIBC reduced resulting in a positive iron balance.

Keywords: Dietary intervention, functional food, Spirulina, hemoglobin, anemia

\section{BACKGROUND:}

Indian economy relies greatly on agriculture. Agriculture is one of the strongholds of the Indian economy and accounted for 15.7 percent of the country's gross domestic product (GDP) in 2008-09. Coffee (Coffea Arabica) is one of the upland crops being cultivated in the hilly terrains of India. Coffee is an agro based industry.

The coffee industry employs one million workers directly or indirectly. In developing countries like India, human labor provides much of the power for physical activity. ${ }^{[1]}$ This is due to the high availability of man power in India and the limited extent of per capita land holdings in which mechanization possibilities are meek. The drudgery encountered by manual laborers in various phases is still a major concern in most industries globally. ${ }^{[2]}$

Nutrition is a vital component in enhancing work efficiency and productivity. According to Longhurst, $1997^{[3]}$ laborers can be described as being in an 'energy trap' i.e. having to maintain subsistence through high levels of energy expenditure leaving little residual energy and health impairment. Nutritional inadequacy, especially protein and iron, impairs the ability of people to perform biologically (diminishing strength and endurance) and this in turn affects working capacity. Many laborers are engaged in heavy physical work and the impact of nutrition on performance is particularly acute for them.

Sustained physical activity implies a steady aerobic replenishment of muscle phosphagen reserves and this process is limited by the rate of transport of oxygen from the atmosphere to the working tissues. ${ }^{[4]}$ As an energy source, carbohydrates depend on oxygen for oxidation. Without oxygen, carbohydrates can function as energy sources but their use would be restricted to a short period of time. In general, the higher the oxygen, the more the carbohydrates that are used as fuel and the greater the efficiency of the system. ${ }^{[5]}$ At this 
juncture, it is imperative to probe into the role played by the respiratory pigment hemoglobin, which through its oxygen carrying capacity can replenish the active working muscle fiber with sufficient oxygen which in turn would suffice the aerobic fragmentation of glycogen and glucose to release energy for physical work. The reduced work capacity due to micronutrient deficiency is sufficiently strong to justify interventions to improve energy efficiency and oxygen transport as a measure of enhancing human capital. ${ }^{[6]}$ Nutritionally high powered functional food such as spirulina, a blue green edible micro-alga has been found to be a rich source of protein, iron and other essential nutrients. ${ }^{[7]}$ It is a rich source of nutraceuticals, the health promoting and disease prevention category of food ingredients. Food and agriculture organization (FAO) of the United States has announced spirulina to be "the most ideal food of the $21^{\text {st }}$ century". World Health Organization (WHO) recommends spirulina as "the best and complete food for tomorrow". The 74 UN World Foodstuff Conference acknowledges spirulina as "Super nutritious food and the most ideal source of nutrition of the $21^{\text {st }}$ century". Spirulina is the richest iron food, containing at least twenty times more iron than any other food. ${ }^{[8]}$ spirulina's iron is easily digestible and twice as absorbable as the iron in vegetables. The blue pigment inspirulina, the phycocyanin forms soluble complexes with iron and other minerals making iron more bio available. ${ }^{[9]}$ Thus, spirulina is reported to be the most nutritious concentrated food known to man. ${ }^{[10]}$

The present study focuses on the nutritional profile of manual coffee plantation laborers belonging to Kodaikannal, a hilly resort of Tamil Nadu. The cause for the acute energy efficiency could be attributed to blood iron metabolic disorder Anemia. Any outcome of this study on the nutritional, especially on the iron metabolic picture of coffee plantation laborers will have a nation wide application because of the possibility for enhancement of productivity which in turn will have a positive impact on the economic growth of the nation.

Against this backdrop, the over all objective of combating the metabolic disorder Anemia and thereby enhancing productivity of coffee plantation laborers through dietary intervention based on nutritional and biochemical assessment was formulated.

The feasible specific objectives of the present study are

To assess the nutritional status and nutrition related problems of the workers.

To design, implement and evaluate impact of dietary intervention for the predominant productivity related nutrition problem.

To perform the cost - benefit analysis of the intervention.

\section{METHODS:}

The study was conducted at Kodaikanal Hill Range of Western Ghats with an altitude of $1300 \mathrm{~m}$ to $1500 \mathrm{~m}$. For the study, permanent coffee plantation laborers aged 26 to 46 years of age were chosen by purposive sampling technique.

Experiments were carried out in three phases. In the first phase, the personal background of the laborers comprising the information on the socio economic background, their physical characteristics, anthropometry and physical fitness levels were assessed.

In the second phase, the nutritional and health status of the laborers, through dietary survey comprising 24 Hour Food Recall record and weighment of cooked food consumed for three consecutive days, clinical and biochemical profile were studied. A pre tested 24-hour recall food recall questionnaire was selected and administered to the plantation workers as a primary technique to measure the habitual dietary intake. This method discloses any 
inadequacies of nutrients from the Basic Five Food Group recommended by Nutrition Expert Group of Indian Council of Medical Research. ${ }^{[11]}$

The consumption of the cooked food by the individual laborers for breakfast, lunch, tea and dinner was recorded using a calibrated kitchen scale. They were then converted to raw weight of foods in grams. ${ }^{[12]}$ The nutritive value of the foods consumed by the laborers, for a day was computed using the food composition tables in Nutritive value of Indian Foods by Gopalan et al. (2007). ${ }^{[13]}$ The mean daily intake of various nutrients by the laborers was estimated over a period of 12 months. Recommended Dietary Allowance for Indians suggested by the Nutrition Expert Group and the deficiency or excess of selected nutrientsprotein, fat, carbohydrates, iron and vitamin $\mathrm{C}$ was interpreted accordingly. As part of the clinical examination, clinical signs seen or felt in superficial epithelial tissues, especially the skin, eyes, hair and buccal mucosa were identified. ${ }^{[14]}$

The biochemical profile included the estimation of blood iron status using the indicesHemoglobin $(\mathrm{Hb})$, Serum Iron, Transferrin Saturation, Serum Ferritin, Total Iron Binding Capacity (TIBC) and Unsaturated Iron Binding Capacity (UIBC).The hemoglobin level was analyzed as per Drabkin's Cyanmethemoglobin method and expressed as g/dl. ${ }^{[15]}$ Serum iron and Total Iron Binding Capacity (TIBC) was estimated by Bathophenanthroline method. ${ }^{[16]}$ Serum ferritin was estimated by Chemi Luminance Immuno Assay. ${ }^{[17]}$ Unsaturated Iron Binding Capacity (UIBC) and percent transferrin saturation were calculated from serum iron and TIBC values. Liver stores were calculated from serum ferritin values i.e., $1 \mathrm{mcg} / \mathrm{l}$ serum ferritin is equivalent to $9 \mathrm{mg}$ liver stores. ${ }^{[18]}$

In the third phase, dietary intervention was implemented with a nutrient rich functional food supplement - spirulina incorporated soup. The supplementation was extended for a period of 120 days. A popular recipe of Tamil Nadu 'rasam' refered to as soup was enriched by incorporating it with $5 \mathrm{~g}$ of spirulina, an amount which is recommended for persons suffering from anemia. ${ }^{[19]}$ After testing the acceptability of spirulina in many food recipes, it was decided to select the traditional recipe 'rasam'. Spirulina, when incorporated in rasam was readily accepted because the spices like pepper, cumin, garlic and tamarind of rasam camouflaged the actual flavor and taste ofspirulina.

The amount of spirulina incorporated was $5 \mathrm{~g}$ and it was optimized by way of organoleptic evaluation. spirulina was incorporated in the soup in various levels like 4, 5 and 6g.They were labeled as sample A, sample B and sample C. Organoleptic evaluation was carried out with 15 panel members by using the five point hedonic scale. ${ }^{[20]}$ Out of the three formulations, sample B i.e., 5g spirulina incorporated soup gained the higher score for overall acceptability and tolerance. It was selected for the dietary intervention. The standardized recipe was tested in the field for its acceptability and then the dietary intervention was implemented.

Before adding spirulina, the soup was filtered to remove the solid particles, so that there was no loss or wastage of spirulina and the laboror consumed the entire amount of Spirulina that was incorporated. The soup was analyzed for iron content by Atomic Absorption Spectrophotometer and the protein content of the spirulina incorporated soup was estimated by Biuret method.

The coffee plantation laborers were grouped into control and the experimental group. The control group was given plain soup and the experimental group was administered with soup incorporated with spirulina. The formulated spirulina incorporated soup was 
supplemented for a period of 120 days, wherein the workers consumed one cup $(150 \mathrm{ml})$ of soup (SIS) everyday before starting the day's work

The impact of intervention on the nutritional and biochemical profile of the laborers was reassessed in similar working conditions. The productivity enhancement in terms of energy and monetary cost was assessed in the pre and post intervention phases.

\section{RESULTS AND DISCUSSION:}

\section{Background details of the coffee plantation laborers}

Initially, the background of the laborers was studied with reference to their socio economic status and physical characteristics. The economic status of the laborers was almost uniform with the daily wage average of Rs 57.5. However, the wages varied depending on the quantity of coffee seeds harvested, whenever harvesting was carried out exclusively by female work force. Majority of the workers (81.5 percent of male laborers and 89.7 percent of female laborers) earned an income between Rs.1000 and Rs.1500 per month. The income distribution indicates that all the laborers were in the stratum below the poverty line with an income of Rs. 2000 and less in a month. The analysis thus makes it clear that the coffee plantation laborers selected for the study belonged to a low socio - economic stratum.

The laborers were observed to have no history of any chronic or acute illness. Their blood pressure was normal at about $118 / 78 \pm 2.3 \mathrm{~mm} . \mathrm{Hg}$ for the male laborers and 116/77 $\pm 2.1 \mathrm{~mm} . \mathrm{Hg}$ for the female laborers. The male and female laborers were observed to have an oral temperature of $98.4 \pm 0.2^{\circ} \mathrm{F}$ and $98.4 \pm 0.8^{\circ} \mathrm{F}$ respectively. The female laborers chosen for the study were non-pregnant and non-lactating.

\section{Nutritional status}

Habitual dietary intake of the coffee plantation laborers

24 hour food recall method

The 24 hour recall food record questionnaire administered to each of the laborers disclosed the adequacy and inadequacies of nutrients from the Basic Five Food Group (Fig.1).

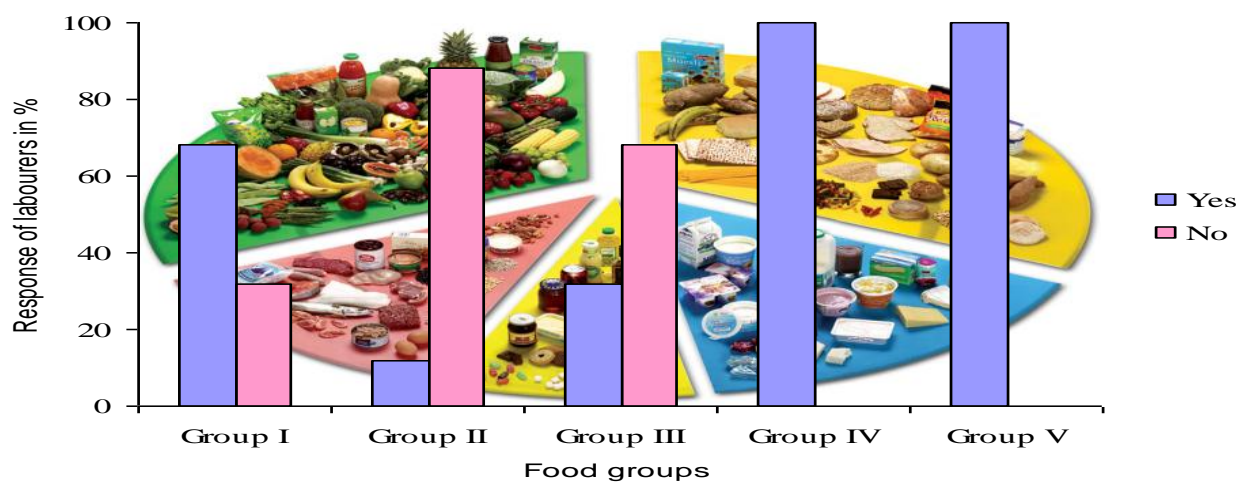

Fig. 1. Response of the coffee plantation laborers with regard to the intake of the Basic Five Food Group of ICM

The percentage of laborers consuming Group I - protein foods (flesh foods and pulses) was 68 while that of Group II - vitamin A and vitamin C rich foods (green leafy vegetables, orange, yellow colored fruits, vegetables and citrus fruits) was 12, Group III - other fruits and 
vegetables comprised 32 percent and those taking Group IV - cereals, roots and tubers and Group V - fats, oils and pure carbohydrates were100 percent.

\section{Weighment of food}

The mean daily intake of various foods and nutrients by the laborers over a period of 12 months and the recommended dietary allowance are given in Table 1 .

Table1. Mean food intake (g/day) in comparison with the recommended food allowance

\begin{tabular}{lllll}
\hline Food items & \multicolumn{2}{c}{ Men } & \multicolumn{2}{c}{ Women } \\
\cline { 2 - 5 } & RDA* & Actual & RDA* & Actual \\
\hline Cereals (g) & 690 & 800 & 480 & 644 \\
Pulses (g) & 65 & 45 & 50 & 30 \\
Milk (ml) & 200 & 30 & 200 & 25 \\
Roots and tubers (g) & 100 & 60 & 100 & 30 \\
Green Leafy Veg(g) & 125 & 30 & 125 & 20 \\
Other vegetables (g) & 100 & 40 & 100 & 30 \\
Fruits (g) & 100 & 30 & 100 & 0 \\
Sugar (g) & 50 & 40 & 40 & 15 \\
Fats \& oils (g) & 45 & 40 & 35 & 40 \\
\hline
\end{tabular}

*ICMR, 2004

The above table gives information regarding the actual intake of foods and the recommended food allowance. ${ }^{[21]}$ The data were collected by weighing the food consumed by the laborers before going for their work (breakfast), during work in the afternoon (lunch) and after returning from their work (dinner). They do not have the habit of consuming early morning bed coffee, midmorning tea and evening tea. The three major meals predominantly consisted of rice. This can be seen in the excess intake of cereals (Table.1) in comparison with the recommended food allowance among all the laborers.

The data obtained through dietary survey via 24 hour recall method and actual weighment of food revealed that the consumption of Group II (citrus fruit, green leafy vegetables, yellow/orange colored fruits and vegetables) was very meager (12\%) while Group IV (cereals and roots and tubers) and Group V (fats, oils, and pure carbohydrates) was 100 percent. Since there was a considerable deficiency in the intake of Group II, especially green leafy vegetables, which is predominantly a rich source of iron, an attempt was made to calculate the intake of iron by the male and female laborers. The average monthly consumption of iron is shown in Fig 2.

The rate of consumption of iron per person per day was found to be $14.71 \pm 1.34 \mathrm{mg}$ for men and $14.67 \pm 1.09 \mathrm{mg}$ for women, which was 47 to 51 percent lower than the recommended dietary allowance (RDA) of $28 \mathrm{mg}$ and $30 \mathrm{mg}$ for male and female laborers (Fig.2).Emphatically, iron content in the diet was so deficient that it was likely to result in low hemoglobin levels. ${ }^{[22]}$ 
Fig 2. Month wise dietary intake of iron (mg/day/head) by the male and female coffee plantation laborers

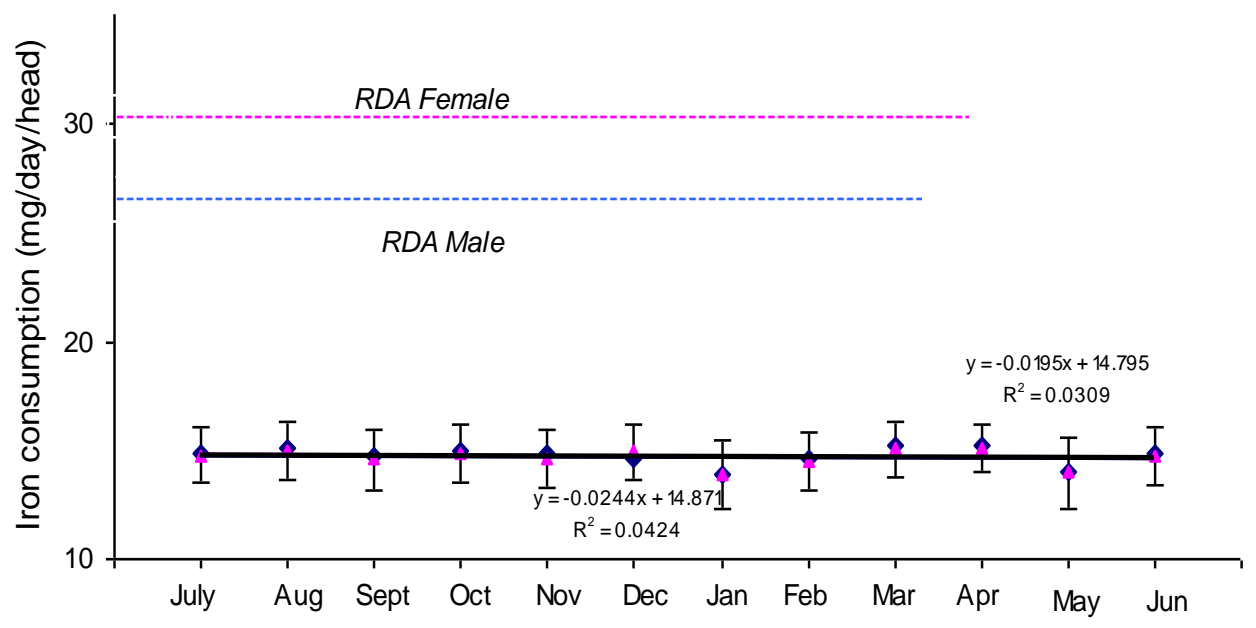

\section{Anthropometry and Clinical Picture}

The anthropometric measurement of the laborers' height in centimeters and weight in kilograms was utilized to calculate the Body Mass Index. Among the 56 laborers chosen for the study, 25 were found to have a BMI in the normal range of 18.5 to $25 \mathrm{~kg} \cdot \mathrm{m}^{-2}$.

The clinical pictures of the selected coffee plantation laborers reveal that the majority of laborers (94 percent) suffered from anemia, a fact corroborated by their eyes showing paleness. They also indicate that around 36 percent of the laborers had glossitis (mouth ulcer), 16 percent suffered from bleeding gums, 4 percent had cheilosis (ulceration of tongue) and 28 percent had angular stomatitis. Fifty six percent showed anemic signs of spooning of nails (koilonychyia) and 89 percent had transverse lines on their nails.

\section{Biochemical evaluation}

The blood iron status was estimated using the indices - Hemoglobin ( $\mathrm{Hb})$, Serum Iron, Transferrin Saturation, Serum Ferritin, Total Iron Binding Capacity (TIBC) and Unsaturated Iron Binding Capacity (UIBC). Since the habitual dietary intake showed deficiency in consumption of iron rich foods and the clinical picture revealed the signs and symptoms of anemia, the blood iron profile was estimated with the specific indicators. Though hemoglobin concentration can indicate anemia, it is not the only diagnostic tool for detecting suspected iron deficiency or anemia. ${ }^{[23]}$ The transferrin saturation is a more reliable measure of gauging iron deficiency than measuring iron itself. ${ }^{[24]}$ It can be used as a gauge of iron supply to the tissues. Serum ferritin is a better index of iron deficiency status of a population as it indicates the iron stores of the body. Table. 2 shows the values of the various blood parameters in comparison with the normal values.

Since the coffee plantation laborers were living at an altitude of more than 1000 meters, the estimated $\mathrm{Hb}$ levels were adjusted for high altitude (i.e.,) $0.4 \mathrm{~g} / \mathrm{dl}$ was added to the observed value a per Hurtado et al.(1989). ${ }^{[25]}$ All the male laborers were observed to be smokers and hence their estimated $\mathrm{Hb}$ levels were adjusted for smokers i.e., observed value was enhanced by $0.3 \mathrm{~g} / \mathrm{dl}$ as per Kapil (2004). ${ }^{[26]}$ 
Table 2. Blood Iron Indices of the coffee plantation laborers

\begin{tabular}{lcccc}
\multirow{2}{*}{ Blood Parameters } & \multicolumn{2}{c}{ Average values } & \multicolumn{2}{c}{ Normal values } \\
& Male & Female & Male & Female \\
\hline Hemoglobin $(\mathrm{g} / \mathrm{dl})$ & $8.6 \pm 1.1$ & $8.1 \pm 1.0$ & $>13$ & $>12$ \\
Serum iron $(\mathrm{mcg} / \mathrm{dl})$ & $47.7 \pm 4.5$ & $42.8 \pm 4.13$ & 65 to 177 & 50 to 170 \\
Serum ferritin (mcg/l) & $11.4 \pm 1.5$ & $8.3 \pm 1.0$ & $>20$ & $>15$ \\
Transferrin sat. (\%) & $9.8 \pm 1.7$ & $7.6 \pm 1.7$ & $>16 \%$ & $>16 \%$ \\
TIBC (mcg/dl) & $483 \pm 39.1$ & $500 \pm 70.8$ & 250 to 450 & 250 to 450 \\
UIBC $(\mathrm{mcg} / \mathrm{dl})$ & $435 \pm 42.8$ & $456 \pm 72.0$ & 110 to 325 & 110 to325 \\
\hline
\end{tabular}

Since the coffee plantation laborers were living at an altitude of more than 1000 meters, the estimated $\mathrm{Hb}$ levels were adjusted for high altitude (i.e.,) $0.4 \mathrm{~g} / \mathrm{dl}$ was added to the observed value a per Hurtado et al.(1989). ${ }^{[25]}$ All the male laborers were observed to be smokers and hence their estimated $\mathrm{Hb}$ levels were adjusted for smokers i.e., observed value was enhanced by $0.3 \mathrm{~g} / \mathrm{dl}$ as per Kapil (2004). ${ }^{[26]}$

The mean levels of hemoglobin, serum iron and serum ferritin of the laborers were found to be below normal among both the male and female laborers. The value for Total Iron Binding Capacity was higher than the normal. These values indicated a complete exhaustion of iron stores and confirmed the presence of iron deficiency anemia. Hemoglobin, serum iron and serum ferritin showed a consistent and progressive fall that resulted in negative iron balance. The TIBC showed a corresponding increase as the decreased iron store in the bone marrow causes increased liver synthesis of transferrin, resulting in an increase in the TIBC. Unsaturated Iron Binding Capacity (UIBC) measures the amount of available iron binding sites on transferrin. The UIBC level was thus, found to be higher than normal, indicating anemia.

The $\mathrm{Hb}$ level ranged from 7.1 to $11.7 \mathrm{~g} / \mathrm{dl}$ in case of men and from 6.8 to $10.7 \mathrm{~g} / \mathrm{dl}$ among the female laborers. The average hemoglobin level was $8.6 \pm 1.12 \mathrm{~g} / \mathrm{dl}$ for men and 8.1 $\pm 1.01 \mathrm{~g} / \mathrm{d}$ l for women which are 28 and 37 percent less than normal. Serum iron ranged from 40.3 to $55.0 \mathrm{mcg} / \mathrm{dl}$ in men and 37.2 to $49 \mathrm{mcg} / \mathrm{dl}$ in women with a mean value of $47.7 \pm 4.5$ $\mathrm{mcg} / \mathrm{dl}$ and $42.8 \pm 4.13 \mathrm{mcg} / \mathrm{dl}$ for the male and female laborers respectively. Serum ferritin level ranged from 9.4 to $15.5 \mathrm{ng} / \mathrm{ml}(\mathrm{mcg} / \mathrm{l})$ with the mean value of $11.4 \pm 1.5 \mathrm{mcg} / \mathrm{l}$ for male laborers which are below the normal level. In the case of women, the average value of serum ferritin was $8.3 \pm 1.0 \mathrm{mcg} / \mathrm{l}$ which was rather below the normal value of $15 \mathrm{mcg} / \mathrm{l}$ and above, indicating very poor iron stores in the laborers. The mean percentage of transferrin saturation was 9.8 percent \pm 1.7 and 7.6 percent \pm 1.7 . The liver iron stores calculated from serum ferritin were in the range of 84 to140 $\mathrm{mg}$ with the mean value of $102 \mathrm{mg} \pm 13.4$ in case of men and 63 to $99 \mathrm{mg}$ with a mean value of $74.3 \mathrm{mg} \pm 4$ for women workers. Correlation between different blood parameters is shown in table 3 .

A positive and significant $(\mathrm{p}<0.01)$ correlation of hemoglobin level to serum iron, serum ferritin and transferrin saturation was observed in both the male and female laborers. The coefficients of correlations (r) were $0.9,1.0$, and 0.9 for men and $0.8,1.0$ and 0.9 for women respectively. However, a negative and significant $(\mathrm{p}<0.01)$ correlation of $\mathrm{Hb}$ level with TIBC and UIBC was observed. $(r=-0.7$ and 0.7$)$. Statistical analysis revealed that the estimated 
blood parameters significantly correlated with each other and thereby confirmed the prevalence of iron deficiency anemia among the male and female laborers.

Table 3 Mean correlation coefficients between blood parameters among the selected coffee plantation laborers.

\begin{tabular}{|c|c|c|c|c|c|c|c|}
\hline Blood parameters & Hemoglobin & $\begin{array}{l}\text { Serum } \\
\text { iron }\end{array}$ & TIBC & $\begin{array}{l}\text { Serum } \\
\text { ferritin }\end{array}$ & $\begin{array}{l}\text { Transferrin } \\
\text { saturation }\end{array}$ & UIBC & $\begin{array}{c}\text { Liver } \\
\text { stores }\end{array}$ \\
\hline Hemoglobin & 1 & & & & & & \\
\hline Serum iron & $0.9 * *$ & 1 & & & & & \\
\hline TIBC & $-0.8 * *$ & $-0.6^{*}$ & & & & & \\
\hline $\begin{array}{l}\text { Serum ferritin } \\
\text { Transferrin }\end{array}$ & $1 * *$ & $0.9 * *$ & $0.8^{* *}$ & 1 & & & \\
\hline saturation & $0.9 * *$ & $0.8^{* *}$ & $0.9^{* *}$ & $0.9 * *$ & 1 & & \\
\hline UIBC & $-0.8 * *$ & $-0.6^{*}$ & $* * 1$ & $0.81 * *$ & $-0.9 * *$ & $\begin{array}{l}1 \\
-\end{array}$ & \\
\hline Liver stores & $1 * *$ & $0.9 * *$ & $0.8^{* *}$ & $1 * *$ & $0.9 * *$ & $0.8^{* *}$ & 1 \\
\hline
\end{tabular}

** - significant at $1 \%$ level.* - significant at $5 \%$ level

Thus, the overall blood picture, with a less than normal value for hemoglobin, serum iron, transferrin saturation, serum ferritin, liver stores and increased value for TIBC and UIBC, confirmed iron deficiency anemia among the laborers chosen for the study. Depending on the concentration of hemoglobin, the laborers who had 10 to $12 \mathrm{~g} / \mathrm{dl}$ of hemoglobin were categorized as those with mild anemia, those with 8.1 to $9.9 \mathrm{~g} / \mathrm{dl}$ were categorized to have moderate anemia and those with 8 or less than 8 g per deciliter were categorized to have severe anemia. ${ }^{[27]}$

Fig 3. Prevalence of mild, moderate and severe anemia among the male and female coffee plantation laborers

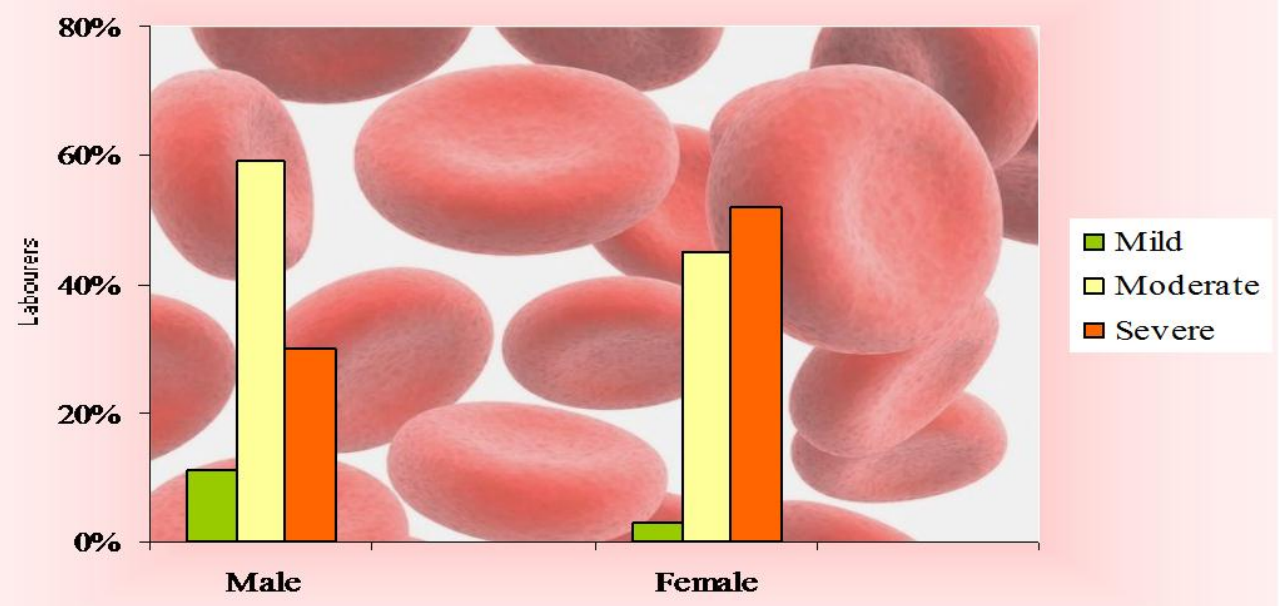


Fig 3 vividly illustrates the percentage of laborers suffering from mild, moderate and severe anemia. It was observed that moderate anemia was prevalent at higher percentage among the male laborers, accounting for 59 percent followed by 30 percent and 11 percent of them suffering from severe and mild anemia respectively. Among the female laborers, 52 percent suffered from severe anemia, followed by 45 percent and 3 percent suffering from moderate and mild anemia.

\section{Need for Intervention}

The findings of the present investigation justify and emphasize the urgency of intervention for these laborers, which would enhance their work capacity. Hence, an attempt was made in this study to design a dietary intervention program, so as to improve the hemoglobin levels of the workers. It was felt that improving the $\mathrm{Hb}$ levels would have a positive impact on the physical, physiological, nutritional and cardio - respiratory fitness of the laborers, which in turn would enhance the work performance and productivity at large.

The present endeavor aims to supplement the daily dietary intake of the laborers with a nutrient rich nutraceutical food supplement - spirulina incorporated soup. The supplementation was extended for a period of 120 days. The laborers were grouped into control and the experimental group. The control group was given plain soup. The experimental group was administered with $150 \mathrm{ml}$ of spirulina Incorporated Soup (SIS) daily before they started their day's physical activity. The laborers were dewormed by administering Albandazole $400 \mathrm{mg}$. After two days, the experimental group was provided with spirulina incorporated soup (SIS).

The protein and iron content of plain soup and spirulina incorporated soup (SIS) were analyzed and tabulated in table 4.

Table 4. Protein and iron content of Plain soup and Spirulina incorporated soup

\begin{tabular}{lccc}
\hline Ingredients & $\begin{array}{c}\text { Amount } \\
(\mathrm{ml})\end{array}$ & $\begin{array}{c}\text { Protein } \\
(\mathrm{g})\end{array}$ & $\begin{array}{c}\text { Iron } \\
(\mathrm{mg})\end{array}$ \\
\hline $\begin{array}{l}\text { Plain soup } \\
\begin{array}{l}\text { Spirulina } \\
\text { Incorporated soup }\end{array}\end{array}$ & 150 & 016 & 0.8 \\
\hline
\end{tabular}

It was inferred that $150 \mathrm{ml}$ of plain soup provided $0.16 \mathrm{~g}$ of protein and $0.8 \mathrm{mg}$ of iron but in case of SIS, the protein content was $27.2 \mathrm{~g}$ and iron content was $6.81 \mathrm{mg}$. Both protein and iron content were enriched because of the addition of Spirulina.

\section{Impact of dietary intervention on the nutritional profile of the laborers}

The supplementation with spirulina incorporated soup (SIS) had a significant impact on the intake of iron which was otherwise quite deficient in the diet pattern of the laborers in the pre-intervention phase. About 14.67 to $14.71 \mathrm{mg}$ of iron per head per day was consumed by the laborers as against the RDA of 28 to $30 \mathrm{mg}$ per head per day. After intervention the iron intake was enhanced by $4.5 \mathrm{mg}$ to $7 \mathrm{mg}$ per head per day which worked to 24 to $27 \mathrm{mg}$ of iron per head per day. 
The intake of protein was also deficient in the pre-intervention phase ranging from 20 to $24 \mathrm{~g}$ per head per day. The intervention with SIS has increased the intake of protein by 6 to $10 \mathrm{~g}$ per head per day i.e., 26 to $30 \mathrm{~g}$ per head per day.

In the present investigation, the experimental findings reveal that the carbohydrate consumption almost fully satisfies the RDA for the day. Since the iron intake was much less than the RDA, the Hb level was far below the normal cut off values. It was found that the condition posed a serious threat as the glycogen stores were not fully oxidized to release the necessary energy required to carry on the daily task. This was due to inadequate oxygen supply to the tissues. The actual existing problem was rectified by improving the iron intake of the laborers' diet which in turn definitely improved the $\mathrm{Hb}$ levels. The oxygen carrying capacity of the hemoglobin would render sufficient oxygen required for oxidation of the blood glucose, liver and muscle glycogen stores to provide the required energy for efficient work performance.

\section{Impact of dietary intervention on the biochemical profile (hemoglobin levels)}

Spirulina being a protein and iron rich food supplement had a positive impact on the hemoglobin synthesis. Though the laborers chosen for the study were of ideal BMI, their hemoglobin levels were below normal. Table 5 shows the hemoglobin levels before (initial/baseline) and after intervention. It also reveals significant difference between the control and experimental group.

Table 5. Impact of dietary intervention on the blood hemoglobin levels of coffee plantation laborers of the control and the experimental group

\begin{tabular}{lcccc}
\hline \multirow{2}{*}{$\begin{array}{l}\text { Days of } \\
\text { supplementation }\end{array}$} & \multicolumn{4}{c}{ Blood hemoglobin levels $\left(\mathrm{g} \cdot \mathrm{dl}^{-1}\right)$} \\
\cline { 2 - 5 } & \multicolumn{2}{c}{ Male laborers } & \multicolumn{2}{c}{ Female laborers } \\
\cline { 2 - 5 } & Control & Experimental & Control & Experimental \\
\hline Initial/Baseline & 9.1 & 9.2 & 9.23 & 8.24 \\
\multirow{4}{*}{40 days } & \pm 0.5 & \pm 0.8 & \pm 0.67 & \pm 0.58 \\
& 9.2 & 9.9 & 9.25 & 8.89 \\
80 days & \pm 0.5 & \pm 0.8 & \pm 0.64 & \pm 0.61 \\
& 9.3 & 11 & 9.25 & 9.88 \\
120 days & \pm 0.5 & \pm 0.8 & \pm 0.6 & \pm 0.7 \\
& 9.4 & 12.3 & 9.35 & 11.1 \\
Difference & \pm 0.6 & \pm 0.9 & \pm 0.6 & \pm 0.7 \\
t value & 0.3 & 3.1 & 0.12 & 2.86 \\
& $0.39^{\mathrm{NS}}$ & $8.29^{* *}$ & $0.15^{\mathrm{NS}}$ & $7.89^{* *}$ \\
\hline
\end{tabular}

**significant at $1 \%$ level; ${ }^{\mathrm{NS}}$ Not significant

The above table shows that there was no significant difference between the initial and the final hemoglobin values in the control group while a significant increase $(\mathrm{t}=8.29 * *$ and $\mathrm{t}=$ $\left.7.89^{* *}\right)$ in the male and female laborers was noticed in the experimental groups.

The data also reveals that among the male laborers, 10 percent who suffered from severe

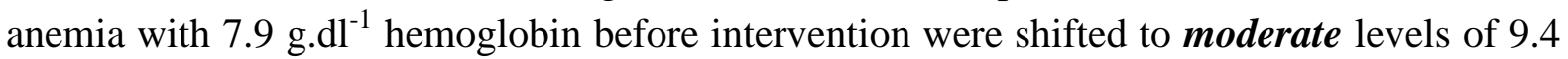
g. $\mathrm{dl}^{-1}$ after intervention, 30 percent who suffered from mild anemia were shifted to normal ones after intervention. Among the 60 percent of male laborers who were moderately anemic, 
50 percent reverted to normalcy. One of the laborers, though mildly anemic had the hemoglobin level increased from 10.2 to $10.9 \mathrm{~g} . \mathrm{dl}^{-1}$.

Fig. 4. shows the hemoglobin levels before and after dietary intervention in the control and the experimental groups of coffee plantation laborers.

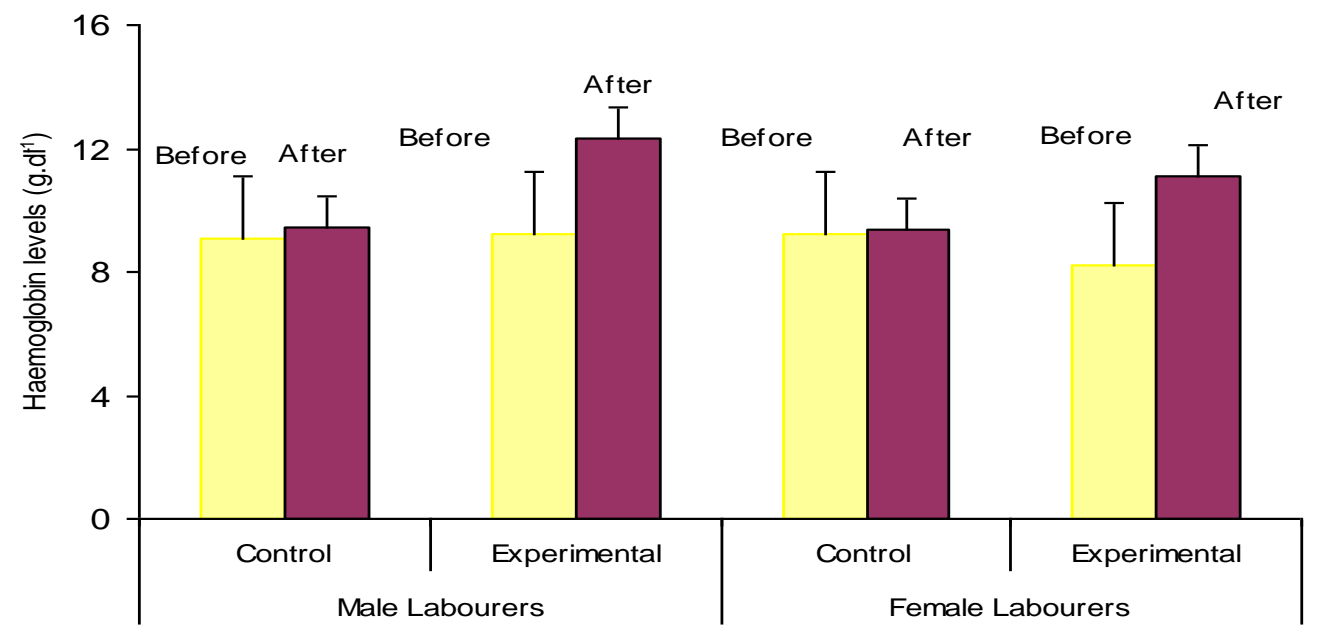

In the present study it was observed that dietary intervention with SIS having $5 \mathrm{~g}$ of spirulina in $150 \mathrm{ml}$ of soup had significantly increased the hemoglobin levels, thereby combating the chronic blood disorder Anemia. This is because the entire amount of iron present in spirulina is made bio available because of the presence of $\beta$-carotene. $\beta$-carotene forms a complex with iron, keeping it soluble in the intestinal lumen and preventing the inhibitory effect of phytates and polyphenols on iron absorption. ${ }^{[28]}$ Also, Phycocyanin, the blue pigment in spirulina, forms soluble complexes with iron and other minerals making iron more bio available. ${ }^{[29]}$

\section{Cost benefit analysis}

\section{Productivity enhancement in terms of energy cost}

The total energy cost of growing and harvesting coffee fruits from one hectare of land is one of the yardsticks for measuring the productivity of the laborers. This was calculated from the energy cost of manual operations like clean weeding, slash weeding, manuring, bush management and harvesting coffee fruits from one hectare of land and it came up to 11,429 $\mathrm{kj} \cdot \mathrm{min}^{-1}$.

The productivity in terms of energy cost of the various coffee plantation activities in the pre and post-intervention periods was computed. The results reveal that among the laborers of the experimental group, the total energy cost of preparing the field, maintaining the coffee plants and harvesting the coffee fruit in the post-intervention phase sums up to 9,361.82 kilo joules per minute as against $11,429 \mathrm{kj} \cdot \mathrm{min}^{-1}$ in the pre-intervention period. There has been a significant decrease by $2,067 \mathrm{kj} \cdot \mathrm{min}^{-1}$ which accounts to an 18.08 percent decrease in the energy expenditure. Among the laborers of the control group, there was no significant change in the total energy cost for the various coffee plantation activities.

The hemoglobin levels had a direct influence on the heart rates of an individual and therefore on the energy expenditure during work. In all the coffee plantation activities, the laborers, seemed to spend varying amounts of energy depending on their $\mathrm{Hb}$ levels i.e., those with higher hemoglobin levels had lower heart rates and hence, lesser energy expenditure. 
Fig 5. Relationship between $\mathrm{Hb}$ levels $\left(\mathrm{g} \cdot \mathrm{dl}^{-1}\right)$ and Energy Expenditure pattern during clean weeding among the coffee plantation laborers

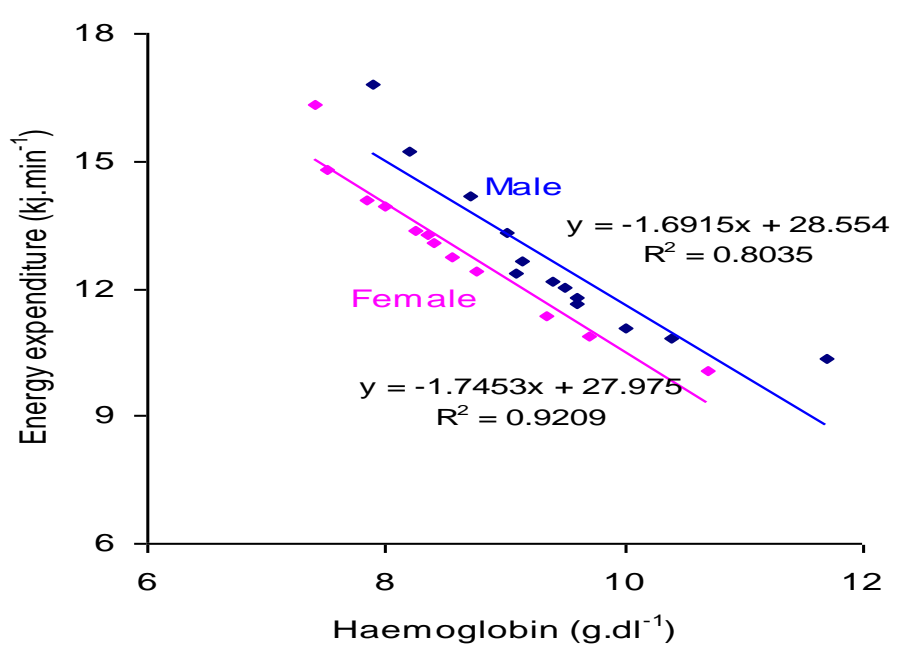

In fig. 5, during clean weeding a strong negative correlation between the hemoglobin levels and energy expenditure pattern was observed among the male and female laborers $\left(R^{2}=0.84\right.$ and $\mathrm{R}^{2}=0.92$ ).A similar correlation was observed in all the plantation activities.

The total energy expenditure for a day ( 24 hours) i.e., 1440 minutes has been computed by the addition of energy expenditure during physical activity, recreation, sleep, basal metabolic rate (BMR) and diet induced thermogenesis (DIT) and graphically represented in fig 6 .

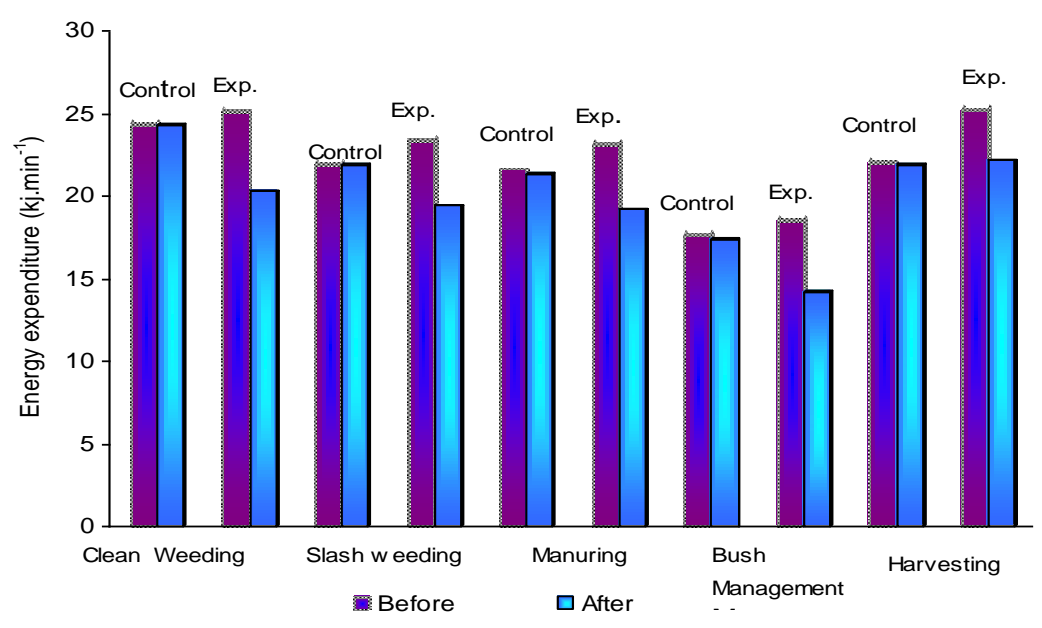

Fig 6. Total energy expenditure before and after intervention in the control and experimental group during coffee plantation activities

On dietary intervention, the total energy expenditure showed a significant decrease $(\mathrm{p}<0.05)$ in the experimental group during the coffee plantation activities while in the control group there was no significant change. The iron rich Spirulina has improved the hemoglobin levels of the laborers in the experimental group, which in turn has enhanced their oxygen carrying capacity replenishing the actively working muscle fiber with sufficient oxygen, thereby 
reducing the high working heart rates experienced by the laborers during the pre- intervention period. This principle of biomechanics and work physiology has consequently reduced the energy cost of the manual coffee plantation operations.

\section{Productivity enhancement in terms of monetary cost}

The number of man days required for cultivating and harvesting coffee fruits in a hectare of land was 529. After dietary intervention, the duration of work has been reduced to save, on an average 453 minutes i.e., 7 hours 50 minutes which works out to almost one man day. For a batch of 20 experimental laborers, i.e., 20 work days, about one man day is saved after intervention. Therefore, for 529 work days, 26 man days are saved per hectare of land.

Supplementation with spirulina incorporated soup has enhanced hemoglobin synthesis, which in turn has increased the efficiency of physical working capacity. Thus, the duration of work has shrunk significantly which cascades to decrease the time spent in performing the physical work. The daily wage for one laborer was $R$ 57.50. If the 26 man days saved are reckoned, it fetches a saving of R 1495 in terms of payable wages.

\section{CONCLUSION:}

The present study has enhanced the nutritional status of the plantation laborers through dietary intervention with functional food supplement spirulina which would have national application resulting in economic growth of the agricultural industry at large. It was observed that the habitual dietary intake showed deficiency in consumption of iron rich foods and the clinical picture revealed the signs and symptoms of anemia The blood iron profile Hemoglobin $(\mathrm{Hb})$, Serum Iron, Transferrin Saturation, Serum Ferritin, Total Iron Binding Capacity (TIBC) and Unsaturated Iron Binding Capacity (UIBC) were greatly influenced by dietary intervention with the functional food spirulina incorporated soup The blood hemoglobin content increased by 21 percent i.e. from 10.9 to $13.3 \mathrm{~g} . \mathrm{dl}^{-1}$. Serum iron, serum ferritin and transferrin levels showed a consistent and progressive rise while TIBC and UIBC reduced resulting in a positive iron balance. Regular consumption of Spirulina Incorporated Soup had improved their efficiency and work performance, delayed the onset of fatigue and decreased the intensity of body discomfort. The duration of work has reduced significantly, decreasing the number of man days and thereby enhancing productivity cost in terms of monetary cost.

Abbreviations: RDA, Recommended Dietary Allowance; Hb, Hemoglobin; TIBC, Total Iron Binding capacity; UIBC, Unsaturated Iron Binding Capacity ; BMR, Basal metabolic rate; DIT, Diet induced thermo genesis

Competing Interests: Researching in role of various Functional foods \& Nutraceuticals in Clinical Nutrition.Right now functioning as Principal Investigator in the Major Research Project sponsored by University Grants Commission.

Author's contribution: All authors have been contributed

Acknowledgements and Funding: The authors express their profound gratitude to Regional Coffee Research Station, Thandikudi for creating a comfortable environment to conduct the 
study at the coffee plantation estate. Sincere thanks to the University Grants Commission for granting permission to carry out the research work under Faculty Development Program

\section{REFERENCES:}

1. Roy SK. Factors affecting the work productivity of Oraon agricultural laborers of Jalpaiguri district, West Bengal. Anthropology and Human Genetics Unit, Indian Statistical Institute, Calcutta. 2002; 35.

2. Marras WS. Occupational low back disorder causation and control. Ergonomics. 2000; 43 (7):880 -902.

3. Longhurst R. Gender dimensions - The energy trap revised, Workshop on Gender differentials in work intensity, sustainability and development, School of development studies, University of East Anglia, Norwich, July 2-4, 1997.

4. Shepard, RJ. Socio economic status and working status - Human physiological work capacity. London, Cambridge University Press. 1978; 81-87.

5. Astrand PO, Rodahl K, Hans A, Dahl MD. Textbook of Work PhysiologyPhysiological Bases of Exercise, Human Kinetics, 4th ed. New York McGraw-Hill. 2003; 369

6. Barac-Nieto M, Spur GB, Maksud, MG and Lotero H. Aerobic work capacity in chronically undernourished adult males. J. Appl. Physiol. Resp Environ. Exercise Physiology. 1980; 44:209.

7. Henrikson, R. 1989. Microalga Spirulina, superalimento del future. Ronore Enterprises, 2ed. Ediciones Urano. Barcelona. Espana. 1989; 222.

8. Seshadri CV. Large scale nutritional supplementation with Spirulina algae, All India coordinated project on Spirulina. Murugappa Chettiar Research Centre. (MCRC), Madras. 1998; 3 - 53.

9. Sen DC and Sarkar S. Beverage and food world. Spirulina: A classical health food. 2004; 46.

10. Murate S. Spirulina - The wonder algae. Nutrition. 1993; 27(2): 5.

11. ICMR. Nutrient Requirement and recommended dietary allowances for Indians. National Institute Nutrition. Hyderabad. 2004; 7.

12. Brahman GNV, Laxmaih A, Mallikharjuna Rao, Gal Reddy. Methodology on assessment of diet and nutritional status of community, National Institute of Nutrition, ICMR, Hyderabad. 2005;

13. Gopalan C, Rama Sastri BV and Balasubramanian SC. Recommended Dietary Allowances for Indians, In: Nutritive value of Indian Foods, Revised and updated by Rao BSN, Deosthale YG and Pant KC. National Institute of Nutrition, ICMR, Hyderabad. 2007.

14. Jelliffee OB and Jelliffee FP. Community Nutritional Assessment with special reference to less technical developed countries. New York, Oxford Medical Publications, Oxford University Press. 1991; 3, 25, 51.

15. Dacie JV and Lewis SM. Practical Haematology, 9th ed. London, Churchhill, Livingstone. 2003.

16. Godkar Praful B, Darshan P, Godkar, Textbook of Medical Laboratory Technology, 2nd ed. Bhalani Publishing House, India. 2004; 817-819.

17. Clausen CA and Fredrick G. Antiody-Medicated Immunochemistry and immunoassay in diseases. In: Dashek William V ed. Methods in biochemistry and molecular 
biology, Boca Raton, FL: CRC Press. 1997; 73 - 78.

18. Cook JD. Clinical evaluation of iron deficiency. Proc. Nutr. Soc. India. 1996; 37:229241.

19. Adams M. Spirulina, Anemia and Food. Natural News. Oct. 10. 2009.

20. Larmond E. Laboratory methods for evaluation of foods. Marie Calendar's Inc.170 E Rincon Street, Corona, California, USA. 1977; linkinghub.elsevier.com /retrieve/pii/0308814691900875.

21. Swaminathan M. Essentials of Foods and Nutrition Vol 2. Bangalore, Bappco Publishers Co Ltd., 2000; 336-347.

22. Brooks GA and Mercier J. Balance of carbohydrates and lipid utilization during exercise the Crossoner concept. American Physiological Society. 1994; 76(6): 2253 2261.

23. Srilakshmi B. Nutrition Science. $3^{\text {rd }}$ ed. New Delhi, New Age International Publishers. 2009; 76-82.

24. Carey BR, Wayne L and Duforn. R. Lab tests online. American Association for Clinical Chemistry (AACC). 2009.

25. Hurtado A, Merino $\mathrm{C}$ and Delgado E. Influence of anoxemia on haemopoietic activities. Archives of Internal Medicine. 1989; 75: 284 - 323.

26. Kapil U, Singh P, Prakash R. Status of iron deficiency anemia in India and indicators for assessment of IDA. In Proceedings of National workshop on Methodologies for assessment of Vitamin A deficiency, Iron deficiency Anemia and Iodine deficiency disorders, AIIMS, New Delhi. Nov 20-23, 2004.

27. Ginder G. Microcytic and hypochromic anemia. In: L.Goldman, D.Ausiello (eds). Cocil Medicine. 23rd ed. Philadelphia, Saunders Elsevier. 2007.

28. Casal MNG, Miguel L, Liseti S, Maria AB, Franklin A, Llovera D et al. Vitamin A and $\beta$-carotene can improve iron absorption from rice, wheat and corn by humans. The Journal of Nutrition. 1998; 128:3:646-650.

29. Sen DC and Sarkar S. Beverage and food world. Spirulina: A classical health food. 2004; 46. 